\title{
Avaliação de impacto ambiental de projetos de intervenções em cursos d'água no Brasil: análise documental e de coerência técnica de estudos ambientais
}

\section{Environmental Impact Assessment of watercourse intervention projects in Brazil: document analysis and technical coherence of environmental studies}

Andreza Tacyana Felix Carvalho' ${ }^{1 *} \mid$ Jaime Joaquim da Silva Pereira Cabral ${ }^{1}$ ORCID ID

Carvalho ATF (D) https://orcid.org/0000-0002-6642-3802
DOI: https://doi.org/10.36659/dae.2020.025

Cabral JJSP (D) https://orcid.org/0000-0002-1348-8004

\section{Resumo}

No Brasil, obras em cursos d'água, como barragens, retificações e dragagens, quando consideradas atividades de significativo impacto ambiental, têm como condicionante para submissão do seu licenciamento ambiental a elaboração de estudos ambientais (EA), contemplando a complexidade dos fatores envolvidos nesses tipos de projeto para que, assim, a equipe técnica do órgão ambiental possa julgar a viabilidade de sua aplicação. Desse modo, este trabalho apresenta, por meio de análise qualitativa por meio de aplicação de protocolo de análise técnico-documental, a coerência técnica dos EAs de projetos de intervenções em cursos d'água. Para isso, a pesquisa de caráter exploratório tem como subsídio documental a utilização de 10 (dez) projetos de obras de barragens, dragagem e retificação de rios, os quais foram submetidos à Avaliação de Impacto Ambiental (AIA) de órgãos ambientais estaduais do país entre os anos de 2010 e 2017.

Palavras-chave: Sustentabilidade. Licenciamento ambiental. Obras em cursos d'água. Parecer técnico. Protocolo de análise documental.

\section{Abstract}

In Brazil, constructions under water courses such as dams, rectifications and dredging when considered activities of significant environmental impact, have as a condition for the submission of their environmental licensing, the elaboration of Environmental Studies (EA) considering the complexity of the factors involved in these types of projects so that the technical team of the environmental agency can judge the feasibility of its application. In this way, this article presents, through qualitative analysis through the application of a technical-document analysis protocol, the technical coherence of the EAs of intervention projects in water courses. For this, the exploratory research has as documental support, the use of 10 (ten) projects of dam works, dredging and rectification of rivers, which were submitted to the Environmental Impact Assessment (EIA) of state environmental agencies of the country, between the years 2010 to 2017.

Keywords: Sustainability. Environmental licensing. Works in water courses. Technical advice. Document analysis protocol.

\footnotetext{
1 Universidade Federal de Pernambuco - Campus Recife - PE - Brasil.

* Autor correspondente: andreza.recursoshidricosagmail.com.
} 


\section{INTRODUÇÃO}

Em um rio, a velocidade das águas depende de fatores importantes, como a declividade do perfil longitudinal, o volume das águas, a forma da seção transversal, o coeficiente de rugosidade do leito e a viscosidade da água, fazendo com que a velocidade das águas tenha variações nos diversos setores do canal no qual ela flui (CHRISTOFOLETTI, 1979; COELHO, 2008).

No entanto, em decorrência do processo acelerado e desordenado de produção e ocupação do espaço urbano, diversas modificações nas condições naturais do meio têm sido observadas, com a alteração das condições naturais de infiltração e a canalização de rios e córregos (HAASE, 2009; CARDOSO, 2011; REZENDE, MIGUEZ \& VERÓL, 2013) alterando significativamente os processos de escoamento natural da bacia hidrográfica a partir do aumento do volume das águas pluviais escoadas superficialmente, incremento das vazões de pico dos corpos d'água, geração de sedimentos, crescente utilização dos recursos hídricos, geração de efluentes e aumento das restrições relativas à qualidade das águas (ZANDONADI et al., 2015; ARAÚjO et al., 2017; CARVALHO, GIRÃO \& CABRAL, 2017).

Portanto, diante desse cenário, admite-se que a utilização dos recursos hídricos e as intervenções nos cursos d'água precisam ser efetuadas tendo em vista a sustentabilidade, promovendo a gestão de recursos hídricos fundamentada em um conjunto de ações destinadas a regular o uso, o controle e a proteção desses recursos, embasados na legislação e nas normas pertinentes.

Como cita Lacerda \& Cândido (2013), esse tipo de gestão deve, inclusive, integrar projetos e atividades com o objetivo de promover a recuperação e a preservação da qualidade e da quantidade dos recursos das bacias hidrográficas, como também a recuperação e a preservação de nascentes, mananciais e cursos d'água em áreas urbanas.
Nesse sentido, apesar de todas as alterações provocadas nos cursos d'água serem entendidas no Brasil, conforme define a Resolução Conama n001, de 23 de janeiro de 1986, como ações geradoras de 'impacto ambiental', são as intervenções projetadas e executadas intencionalmente com propósitos sociais e econômicos como, por exemplo, as obras de barragens, dragagens e retificações fluviais, que são oficialmente objeto de análise do instrumento de Avaliação de Impacto Ambiental (AIA). E, embora a implantação desses projetos possa proporcionar impactos positivos diretos no crescimento das economias locais, bem como no bem-estar da sociedade, estes podem gerar diversas degradações ambientais e provocar impactos negativos involuntários nos ambientes circundantes.

Conforme estabelecido pela Lei Federal $n^{\circ}$ $6.938 / 1981$, esses empreendimentos ou/e atividades, quando submetidos ao processo de licenciamento ambiental, devem, por meio de documentos de Estudos Ambientais (EAs) e exigências definidas pelo órgão ambiental competente, apresentar os possíveis impactos ambientais, sociais e econômicos (negativos e positivos) decorrentes de sua instalação e operação. Nesses estudos, "quanto melhor definidos os conceitos que utiliza e mais articulado em suas partes, maiores as possibilidades de este documento avaliar exigências sociais, ambientais e econômicas do empreendimento ou atendê-las da forma o mais equitativa possível” (VIEGAS, 2009).

Esta pesquisa não é tarefa simples, uma vez que, segundo Viegas (2009), o EIA envolve realidades diversas e imbricadas nos planos ambiental, social, econômico, tecnológico e cultural. Não há como reduzi-lo a um plano de análise sem perder o direcionamento integralizador que caracteriza a sustentabilidade e que constitui uma das principais linhas recentes de investigação sobre ele. 
Desse modo, considera-se que "(...) a tomada de decisões ambientais implica em processos pelos quais escolhas são feitas sobre atividades que usam recursos naturais ou alteram a paisagem de alguma forma. E que essas escolhas têm consequências para o meio ambiente e para a sociedade" (WILLIAMS \& DUPUY, 2017), bem como que "(...) a análise do conteúdo dos EAs deve ser feita com base em certos critérios preestabelecidos, por meio dos quais se avalia a qualidade e a adequação dos estudos apresentados" (SÁNCHEZ, 2008), entende-se que a deliberação pela aplicação do citado projeto, baseada no julgamento ambiental do órgão ambiental, é de cunho não apenas ambiental, mas também social e econômica.

Diante da citada problemática, este trabalho destina-se a analisar qualitativamente a coerência técnico-documental de Estudos Ambientais (EAs) de projetos de intervenções em cursos d'água perenes, objetos do licenciamento ambiental de órgãos ambientais brasileiros, frente ao atendimento de critérios técnico-documentais estabelecidos pela legislação ambiental vigente do Brasil.

Para isto, o trabalho de caráter exploratório utiliza-se metodologicamente de revisão bibliográfica, pesquisa documental e a aplicação de protocolo de análise técnico-documental construído, para efetuar a citada análise em 10 (dez) estudos ambientais componentes de processos de licenciamento ambiental (licença prévia, licença de instalação ou autorização ambiental) de projetos de intervenções em cursos d'água (barragens, dragagem e retificação de rios), os quais foram submetidos, entre os anos de 2010 e 2017, à AIA, aos seguintes órgãos ambientais brasileiros: Agência Estadual de Meio Ambiente de Pernambuco (CPRH), Companhia Ambiental do Estado de São Paulo (Cetesb) e Secretaria de Estado de Meio Ambiente e Desenvolvimento Sustentável de Minas Gerais (SEMAD).

\section{SUSTENTABILIDADE E AVALIAÇÃO DE}

\section{IMPACTO AMBIENTAL NO PROCESSO DE} LICENCIAMENTO AMBIENTAL NO BRASIL

A sustentabilidade envolve a conservação de "algo", para as gerações futuras (MARTINET, 2011). O conceito contempla em seu discurso a integração pragmática do desenvolvimento e de meio ambiente; a ideia de limitações nas atividades humanas; o processo de mudança/transição direcionada e, por fim, a promoção da resiliência e da justiça (POPE, 2016). Todavia, entende-se que a definição do termo "sustentabilidade", e/ ou "desenvolvimento sustentável", não está de modo algum acordada e está sujeita a julgamentos de valor (BELL \& MORSE, 2008).

Segundo Van Bellen (2004), Patterson (2010) e Fischer \& Jha-Thakur (2013), por se tratar de um processo contínuo e complexo, existem várias abordagens que procuram explicar o seu conceito, e sua teoria e práticas estão em constante progresso, no qual "deve-se adotar uma abordagem holística para entender as interações dinâmicas entre a natureza e a sociedade e avaliar a vulnerabilidade e resiliência de sistemas sociais e ecológicos complexos” (SALA et al., 2015).

A AIA, que em todo mundo foi formalizada e se consolidou pela via legal, é apenas um dos instrumentos empregados para tentar compatibilizar desenvolvimento econômico e social com proteção e melhoria da qualidade ambiental, tendo como ideal o desenvolvimento sustentável (SÁNCHEZ, 2013; TORO et al. 2013; BRAGAGNOLO et al., 2017). Historicamente, a AIA surgiu por uma necessidade de harmonizar o desenvolvimento econômico e a proteção ambiental, no sentido de um desenvolvimento sustentável do ponto de vista ambiental, econômico e social, tal como afirmado na Conferência de Estocolmo sobre Meio Ambiente e Desenvolvimento Humano em 1972 (NEVES et al., 2013). 
De acordo com Moreira (1985), Moraes \& Santos (2004) e Galás et al. (2015), os Estados Unidos da América foi o primeiro país a adotar uma legislação específica sobre a Avaliação, denominada de National Environmental Policy Act (NEPA), datada de 1969. Para Stamm (2003), essa lei estabelecia a necessidade da preparação de uma declaração prevendo os impactos ambientais para qualquer tipo de projeto.

Bond et al. (2011) citam que o fato de o desenvolvimento do uso do solo ter o potencial de causar impactos ambientais há muito tempo reconhecido e, desde 1988, como resultado de obrigações impostas pela Diretiva de Avaliação de Impacto Ambiental do Conselho das Comunidades Europeias, conduziu à determinação da exigência de que projetos com impactos ambientais potencialmente significativos devem ser submetidos à AIA.

Em 1994, o Grupo criou um quadro de referência para a implementação do sistema de AIA nos sistemas jurídicos dos Estados Membros da União Europeia, incluindo os países pertencentes ao Grupo Visegrad (V4): Polônia, Eslováquia, República Checa e Hungria. (LEE et al., 1999; GALÁS et al., 2015). Tal procedimento trouxe orientação por meio do fornecimento de informações aos tomadores de decisão, detalhando as implicações ambientais da concessão e permissão para possível aplicação dos projetos em questão.

Nessa perspectiva, Morgan (2012) menciona que os procedimentos de AIA são empregados no mínimo em 181 países. Entretanto, conforme Galás et al. (2015), cada país tem diferenças em seu processo de avaliação e em sua legislação nacional de AIA decorrentes de suas próprias peculiaridades. $E$ "(...) sua utilidade, no entanto, depende de como elas são implementadas e de se as descobertas são usadas na tomada de decisões públicas" (WILLIAMS \& DUPUY, 2017).

Todavia, diferentemente de países desenvolvidos, que implantaram a AIA em resposta a pres- sões sociais e ao avanço da consciência ambientalista (MORGAN, 2012), Viegas (2009) cita que, no Brasil, ela foi adotada principalmente por exigência dos organismos multilaterais de financiamento (Banco Interamericano de Desenvolvimento - BID e Banco Mundial para Reconstrução e Desenvolvimento - BIRD) e teve suas origens na Política Nacional do Meio Ambiente (Lei Federal $n^{\circ}$ 6.938, de 31 de agosto de 1981) (BRASIL, 1981) e, antes, na Lei de Zoneamento Industrial (Lei Federal $n^{\circ} 6.830$, de 22 de setembro de 1980) (BRASIL, 1980).

De acordo com a Cetesb (2014), os sistemas de AIA variam muito entre os vários países. Alguns são leis, normas ou estatutos, que são exigidos pelas autoridades antes da permissão de implementação de um projeto. Em outros casos, apenas diretrizes sobre AIA foram estabelecidas, impondo algumas obrigações para os órgãos governamentais.

Para Sánchez (2008), quando a AIA foi introduzida no Brasil, já havia no plano federal diversos instrumentos legais no campo do meio ambiente - então, a AIA soma-se a um quadro preexistente, mas o modifica, ao estabelecer, de maneira incontestável, a importância dos enfoques preventivos, a prevenção do dano ambiental e a prevenção de degradação ambiental.

Assim, “(...) a fim de identificar, prever, interpretar e prevenir as consequências ou efeitos ambientais que determinadas ações, planos, programas ou projetos possam causar à saúde, ao bem-estar humano e ao entorno, a Resolução do Conama $n^{\circ}$ 001/1986 (BRASIL, 1986) introduziu a AIA na forma do estudo ambiental, estabelecendo um padrão técnico-científico para sua legitimação perante os setores e os segmentos sociais" (CARDOSO et al., 2015).

E, apesar de a avaliação, por sua própria natureza, ser um procedimento técnico, ela contribui muito para produção política e técnica-científi- 
ca. Logo, pode-se definir que "a AlA é um procedimento administrativo de tomada de decisão, que vem com uma série de métodos que podem ser aplicados em diferentes situações, que vão desde projetos individuais às políticas, planos e programas" (FISCHER \& JHA-THAKUR, 2013). Consiste em uma família de ferramentas, incluindo avaliação de impacto social, avaliação de impacto da biodiversidade e avaliação de impacto na saúde (LEUNG et al., 2015).

De tal modo, Sánchez (2008) orienta que toda AIA tenha os seguintes pontos em comum: é um conjunto estruturado de procedimentos; é regida por legislação ou regulamentação específica; é documentada; envolve diversos participantes; é voltada à análise de viabilidade ambiental, ou seja, seus critérios devem servir para avaliar se e até que ponto um determinado projeto é compatível com as condições do ambiente em que pretende se inserir.

No Brasil, é por meio do licenciamento ambiental, um dos principais instrumentos de comando e controle da Política Nacional de Meio Ambiente do Brasil, estabelecido pela mesma Lei, que "a Administração Pública busca exercer o necessário controle sobre as atividades humanas que interferem nas condições ambientais, de forma a compatibilizar o desenvolvimento econômico com a preservação do equilíbrio ecológico" (MILARÉ, 2009).

O instrumento como um "(...) processo administrativo, eivado de instrumentos de gestão ambiental e participação pública, propicia a avaliação dos impactos socioambientais dos determinados projetos, visando a uma decisão administrativa sensata quanto ao deferimento ou indeferimento de uma licença ambiental pelo órgão ambiental competente" (TEIXEIRA, 2010). Por meio dele, conforme a Resolução Conama $n^{\circ}$ 237, de 19 de dezembro de 1997, o órgão ambiental competente licencia a localização, ins- talação, ampliação e a operação de empreendimentos e atividades utilizadoras de recursos ambientais, consideradas efetiva ou potencialmente poluidoras ou daquelas que, sob qualquer forma, possam causar degradação ambiental, considerando as disposições legais e regulamentares e as normas técnicas aplicáveis ao caso.

Entretanto, “(...) seus objetivos limitam-se a subsidiar as decisões de aprovação de projetos de empreendimentos individuais, e não os processos de planejamento e as decisões políticas e estratégicas que os originam" (MINISTÉRIO DO MEIO AMBIENTE, 2002). No caso de projetos e atividades que possam causar significativa degradação ambiental, a legislação atual do Brasil exige que EAs guiem o órgão ambiental para autorizar (ou não) as iniciativas de desenvolvimento propostas (BRAGAGNOLO et al., 2017).

De acordo com a Resolução Conama $n^{\circ} 237$, de 19 de dezembro de 1997, são EAs todos e quaisquer estudos relativos aos aspectos ambientais relacionados à localização, instalação, operação e ampliação de uma atividade ou empreendimento, apresentado como subsídio para a análise da licença requerida. Cabe principalmente às equipes elaboradoras desses estudos estabelecer e seguir instrumentos que possam complementar a legislação, fazendo-se tecnicamente corretos, revisáveis, eficientes e capazes de serem traduzidos em linguagem simples para acesso e compreensão do público em geral. Essa tarefa, contudo, não é simples (SÁNCHEZ, 2008; VIEGAS, 2009; NEVES, 2013).

Ao planejar o estudo, o analista se depara com a necessidade de estabelecer critérios para incluir ou excluir determinado impacto potencial da relação daqueles que merecerão estudos e levantamentos detalhados durante a preparação dos estudos. (...) em termos práticos, pelo menos três tipos de critério têm se mostrado úteis para definir as questões relevantes em um EIA: a ex- 
periência profissional dos analistas; a opinião do público e os requisitos legais (SÁNCHEZ, 2008). Reconhecer, compreender e considerar a incerteza é, portanto, essencial para garantir uma boa AIA (LEUNG et al., 2015).

E, apesar de possuir objetivos definidos e apresentados de forma explícita pelo conjunto de normas, compreende-se que o licenciamento ambiental depende de ferramentas, documentos e EAs que possam dar subsídios à adequada análise e avaliação ambiental dos empreendimentos/atividades em questão, tais como: Termo de Referência (TR), Estudo de Impacto Ambiental (EIA), Relatório de Impacto Ambiental (RIMA), Plano de Controle Ambiental (PCA), Relatório de Controle Ambiental (RCA), Plano de Recuperação de Áreas Degradadas (PRAD) e Parecer Técnico (PT).

O "órgão ambiental competente através de equipe especializada e fundamentado nestes estudos, inicialmente deve ponderar de alguma forma a consecução do empreendimento/atividade em questão, em viabilidade à sustentabilidade e, posteriormente no caso de compatibilidade, deve direcionar por meio de exigências e requisitos, medidas que projetem promover a preservação, a conservação e/ou a restauração da qualidade ambiental” (SÁNCHEZ, 2008; VALINHAS, 2010).

Portanto, entende-se que o Estado, por meio do órgão ambiental, ao assumir essa competência, é responsável por indicar que atividades e/ou empreendimentos devem passar por exigências, restrições e observações para sua instalação e operação, bem como em alguns casos, ser exigida a reposição do recurso pela degradação ambiental.

\subsection{Licenciamento Ambiental de projetos de intervenções em cursos d'água}

O processo de composição do licenciamento ambiental é um sistema aberto, integrado e multidisciplinar, que deve estar embasado em prin- cípios e conhecimentos legais, técnicos e científicos, haja vista a diversidade e complexidade de projetos e atividades que os demandam.

Dentro do processo de AIA, a etapa de avaliação ou análise técnica dos Estudos Ambientais (EAs) apresentados tem a função de verificar a conformidade desses estudos com os critérios estabelecidos (SÁNCHEZ, 2008). Diante dessa questão, utiliza-se uma ferramenta denominada Termo de Referência (TR) para “(...) estabelecer as diretrizes orientadoras, conteúdo e abrangência do estudo exigido do empreendedor, em etapa antecedente à implantação da atividade modificadora do meio ambiente" (ABSY et al., 1995).

Para os casos de projetos de barragens, dragagens e retificação de rios, assim como para outras obras de significativo impacto ambiental, Sánchez (2013) cita que o TR deve orientar a elaboração, definir o conteúdo, abrangência, métodos e estabelecer a estrutura desses EAs. Além disso, a ferramenta, como documento norteador, deve integrar as demandas e pontos de vista de todos os interessados na atividade/empreendimento proposto.

Considerando a conjuntura do desenvolvimento metodológico da área de licenciamento ambiental de obras de intervenções em cursos d'água, conforme cita Cruz et al. (2010), há uma grande heterogeneidade de comportamentos dos órgãos ambientais, dada a sua volatilidade de pessoal ou devido ao peso político da área ambiental sobre as decisões referentes aos grandes projetos de investimentos. As incertezas relativas aos desenvolvimentos técnico-científicos recentes e a pouca disponibilidade de pessoal qualificado nessas áreas novas têm levado a uma grande variedade de comportamentos institucionais, resultando em processos de licenciamento que não necessariamente acompanham os avanços metodológicos refletidos em nível federal nas unidades da federação. 
Além disso, no processo de licenciamento ambiental de intervenções em cursos d'água, no geral, o rio não é considerado um sistema. Sobre isso, Cruz et al. (2010) cita que essa prática não está de acordo com o que prevê a legislação ambiental, a qual prevê que a unidade de planejamento é a bacia hidrográfica e que todos os estudos devem levar em conta os efeitos na mesma. Normalmente, o atendimento a esse preceito é formalmente contemplado informando a bacia hidrográfica na qual está inserido o empreendimento, e não pelo estudo da propagação dos impactos em toda a bacia através da conexão da rede hidrográfica.

Desse modo, o licenciamento ambiental, apesar de ter como fundamento básico, para análise para esses tipos de projeto, a bacia hidrográfica como unidade de planejamento, sua análise ambiental está embasada em informações e dados locais tendo, assim, uma lacuna referente aos impactos gerados ao longo de toda a bacia hidrográfica, uma vez que tem o curso d’água como principal elemento geomorfológico estruturador da dinâmica natural dessa unidade.

\subsection{Dos Estudos Ambientais à Avaliação de Impacto Ambiental de projetos de intervenções em rios}

De acordo com a classificação e informações do Portal Nacional do Licenciamento Ambiental do
MMA (2018), entre o período de 01/01/2010 a 31/12/2017, 30.856 licenças ambientais estaduais do tipo: prévia, de instalação, prévia e de instalação, simplificadas e autorização ambiental, na situação de vigentes, concluídas ou vencidas, foram concedidas para o enquadramento de tipologias de hidráulicas como obras de instalação de barragens e diques; dragagem e derrocamento em corpos d'água e retificação e canalização de cursos d'água.

Apesar da elaboração de alguns EAs ser comumente exigida na maioria dos Estados do Brasil, o conteúdo desses estudos e a fase do licenciamento em que poderão ser solicitados podem variar de Estado para Estado, de acordo com legislações e procedimentos próprios. "Em muitos estados, o EA é substituído por uma listagem de documentos pré-determinados de acordo com a atividade e porte do empreendimento" (MMA, 2017).

A rigor, o conjunto de atos que compõem a documentação que subsidiará a emissão de uma licença ambiental constitui-se em processo administrativo, que tramita perante o órgão ambiental competente (TEIXEIRA, 2010). De acordo com Sánchez (2008), a definição dos estudos técnicos necessários ao licenciamento cabe ao órgão licenciador. Todavia, nos casos de empreendimentos que tenham o potencial de causar degradação significativa, sempre deverá ser exigido o EIA, nos termos do dispositivo constitucional como mostra a Fig. 1. 


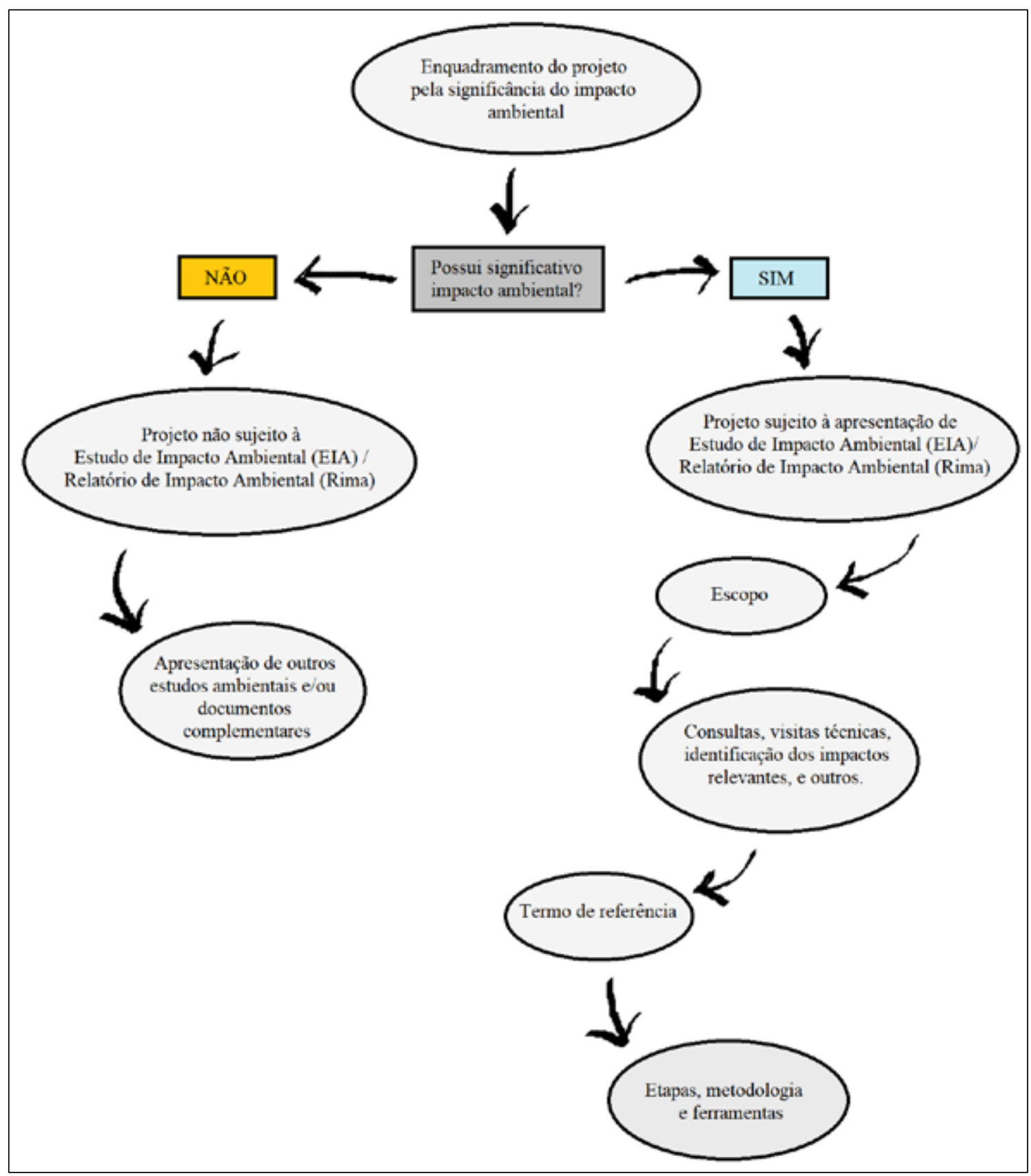

Figura 1 - Representação das etapas preliminares à elaboração de um EIA Fonte: Elaborado pela autora (2017), adaptado de Viegas (2009)

Nos ElAs, são abordados os aspectos técnicos necessários à avaliação dos impactos ambientais a serem gerados pelo empreendimento (PERMINOVA, 2016; MMA, 2017). Além disso, esse tipo de estudo “(...) deve ser transparente, responsável e participativo, a fim de identificar corretamente os impactos e as medidas de mitigação e, assim, permitir decisões que reduzem os custos sociais e ambientais que os indivíduos devem suportar" (WILLIAMS \& DUPUY, 2017).

Para Viegas (2009), a complexidade inerente a esse tipo de estudo requer a conjugação de elementos do ambiente natural - quanto à sua identificação, impactos sofridos e prognósticos futuros - e do ambiente criado socioeconômica 
e culturalmente. Ou seja, o EIA evoca a si a pluralidade e a diversidade de disciplinas e visões de mundo que o ensejam.

Desse modo, conforme a Resolução Conama $n^{\circ}$ 001/1986, para os casos de obras hidráulicas para exploração de recursos hídricos, tais como: barragem para fins hidrelétricos, acima de 10MW, de saneamento ou de irrigação, abertura de canais para navegação, drenagem e irrigação, retificação de cursos d'água, abertura de barras e embocaduras, transposição de bacias e diques são objetos de AIA, a partir da análise de Estudo de Impacto Ambiental (EIA) e Relatório de Impacto Ambiental (Rima).

Segundo Teixeira (2010), a pretensão de instalação desse tipo de obra traz consigo, além da obrigatória elaboração de EIA e Rima a atestar a viabilidade socioambiental do projeto, uma série de etapas a ser observada no referido processo, qualificando-o como um processo administrativo de procedimento complexo.

Além disso, destaca-se que o "EIA e Rima, bem como as demais AIAs, têm de ser exigidos, elaborados e aprovados antes da concessão da licença prévia, até porque se trata de pré-requisito" (MIRRA, 2002). Todavia, alguns casos podem não ser considerados pelo órgão ambiental competente como empreendimento/atividade de significativo impacto ambiental. Nessa situação, são exigidos apenas estudos ambientais de menor complexidade para compor o processo de licenciamento ambiental.

Assim, independentemente dos estudos exigidos, mas diante da complexidade desses ti- pos projetos e de seus impactos no ambiente, a equipe técnica elaboradora e, principalmente, a equipe avaliadora em âmbito governamental, devem estar embasadas de informações e dados coerentes e seguros para oferecer embasamento técnico-científico à composição de avaliação conclusiva e, consequentemente, posterior tomada de decisão sobre o desenvolvimento do projeto proposto.

\section{METODOLOGIA DE TRABALHO}

Este trabalho, caracterizado como pesquisa do tipo descritiva e exploratória de caráter qualitativo, tem como enfoque o levantamento de dados e informações obtidas por meio de revisão bibliográfica e pesquisa documental, tendo como grupo amostral 10 (dez) estudos ambientais (EIA, RIMA, Relatório Ambiental Simplificado (RAS) e outros), componentes de processos de licenciamento ambiental (licenças prévias, licenças de instalação ou autorizações ambientais) de projetos de intervenções em rios (obras de construção de barragem, dragagem, retificação e requalificação de cursos d'águas), selecionados aleatoriamente e submetidos entre os anos de 2010 a 2017 à AIA dos seguintes órgãos ambientais estaduais brasileiros: Agência Estadual de Meio Ambiente de Pernambuco (CPRH), à Companhia Ambiental do Estado de São Paulo (Cetesb) e à Secretaria de Estado de Meio Ambiente e Desenvolvimento Sustentável de Minas Gerais (SEMAD) (Quadro 1). 
Quadro 1 - Processos de projetos de intervenções em cursos d'água submetidos ao licenciamento ambiental e consultados em arquivos de órgãos ambientais estaduais do Brasil

\begin{tabular}{|c|c|c|c|c|c|c|}
\hline $\begin{array}{c}\text { No de identificação } \\
\text { de projeto }\end{array}$ & No do processo & Ano de origem & Tipo de projeto & $\begin{array}{c}\text { Tipo de licença } \\
\text { ambiental }\end{array}$ & $\begin{array}{c}\text { Órgão de } \\
\text { Origem }\end{array}$ & Situação \\
\hline 01 & 011851 & 2010 & $\begin{array}{c}\text { Retificação de curso } \\
\text { d'água }\end{array}$ & $\begin{array}{c}\text { Licença de } \\
\text { instalação }\end{array}$ & SEMAD & Deferido \\
\hline 02 & 001637 & 2011 & $\begin{array}{c}\text { Barragem para } \\
\text { abastecimento }\end{array}$ & Licença prévia & CPRH & Deferido \\
\hline 03 & 000095 & 2012 & $\begin{array}{c}\text { Barragem para } \\
\text { abastecimento }\end{array}$ & Licença prévia & CPRH & Deferido \\
\hline 04 & 011794 & 2012 & $\begin{array}{c}\text { Requalificação } \\
\text { fluvial }\end{array}$ & $\begin{array}{c}\text { Licença prévia e } \\
\text { de instalação }\end{array}$ & CPRH & Em análise \\
\hline 05 & 000189 & 2013 & $\begin{array}{c}\text { Barragem para } \\
\text { abastecimento }\end{array}$ & Licença prévia & Cetesb & Deferido \\
\hline 06 & 008765 & 2013 & $\begin{array}{c}\text { Barragem para } \\
\text { contenção de cheias }\end{array}$ & Licença prévia & SEMAD & Deferido \\
\hline 07 & 018361 & 2014 & $\begin{array}{c}\text { Dragagem } \\
\text { Larragem para } \\
\text { abastecimento e } \\
\text { contenção de cheias }\end{array}$ & Licença prévia & Cetesb & Deferido \\
\hline 08 & 000113 & 2014 & Ambiental & SEMAD & Deferido \\
\hline 09 & 008598 & 2016 & $\begin{array}{c}\text { Requalificação } \\
\text { fluvial }\end{array}$ & $\begin{array}{c}\text { Licença de } \\
\text { instalação }\end{array}$ & CPRH & Em análise \\
\hline 10 & 001733 & 2017 & $\begin{array}{c}\text { Retificação de curso } \\
\text { d'água }\end{array}$ & $\begin{array}{c}\text { Licença de } \\
\text { instalação }\end{array}$ & CPRH & Deferido \\
\hline
\end{tabular}

Fonte: Elaborado pela autora

Desse modo, para consecução do objetivo, a pesquisa está estruturada em etapas que se desdobram em pré-análise e exploração de material documental e bibliográfico; coleta e tratamento de informações e dados documentais e bibliográficos; desenvolvimento de protocolo de análise dos dados e informações; e, por fim, apresentação e interpretação dos resultados obtidos, como mostra a Fig. 2.

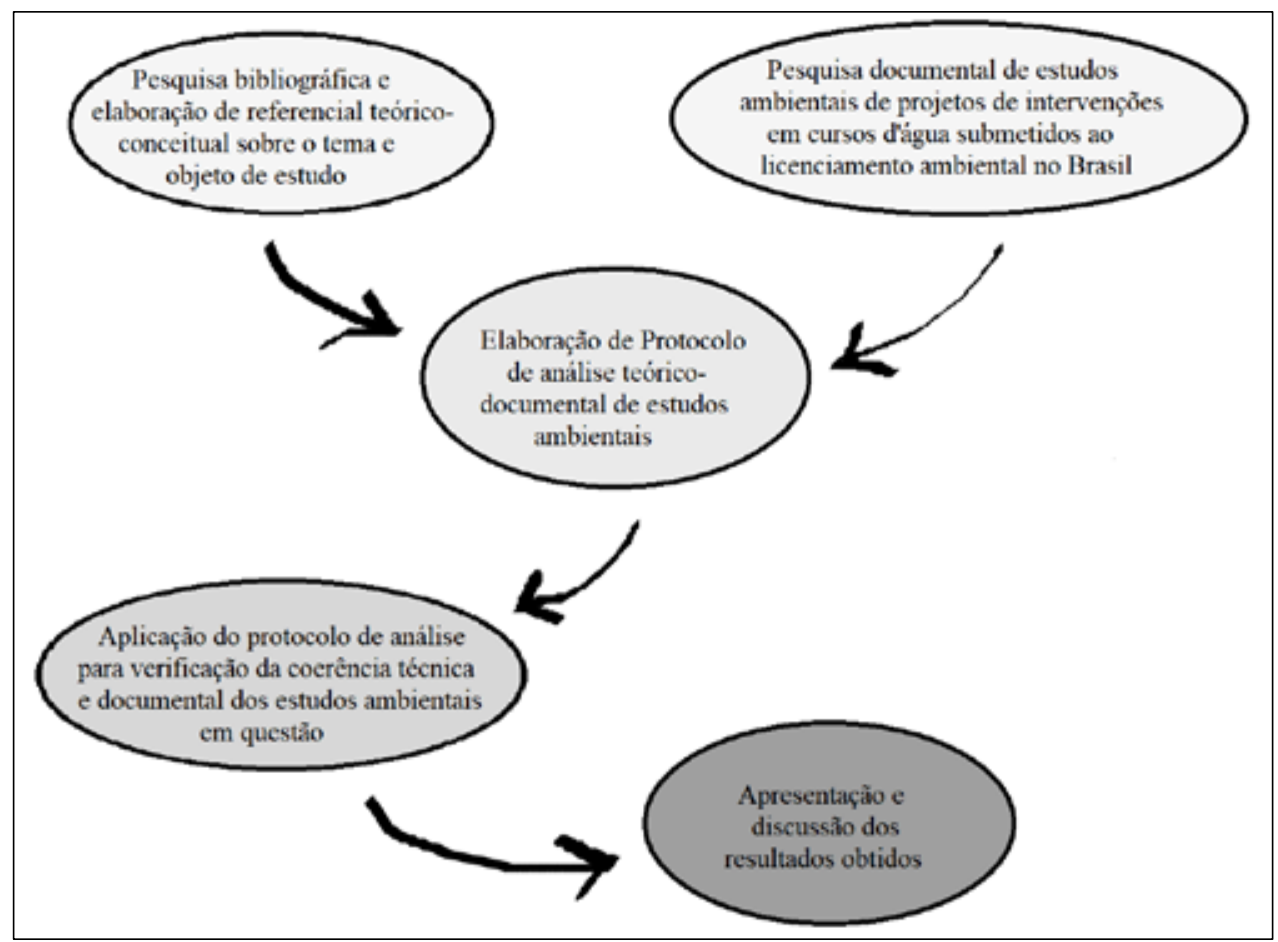

Figura 2 - Representação das etapas metodológicas para consecução do objetivo da pesquisa Fonte: Elaborada pela autora 
Com relação à pesquisa documental, esta confere embasamento à discussão quanto à análise de coerência, a qual incide na verificação da consistência dos dados e informações apresentadas e fundamentadoras dos estudos ambientais solicitados no licenciamento ambiental. Assim, como ferramenta para análise da documentação obtida na pesquisa, é elaborado um protocolo de análise documental de caráter qualitativo, à luz da experiência técnica do autor deste trabalho, sendo baseado na Resolução Conama nº 01/1986 e nos trabalhos técnicos de Lee (1999), Sánchez (2008), Viegas (2009), Cruz (2013) e Canter (2014).

Esse protocolo elaborado de forma genérica, é composto por 10 (dez) critérios de análises adaptados de Bojórquez-Tapia \& Garcia (1998), onde cada um deles foi subdividido, tendo o total de 18 (dezoito) itens de análise. Para cada item foi determinada uma pontuação escalar em números inteiros, cuja gradação de menor para maior corresponde ao grau crescente de cumprimento do critério. Foram convencionadas de zero (0) a dois (2); de zero (0) a três (3); ou de zero (0) a cinco (5), a depender do critério. A pontuação zero (0) representa o não cumprimento do critério exposto, e o número mais elevado apresentado, para cada critério, o pleno cumprimento do mesmo, finalizando o escore total de 45 (quarenta e cinco) pontos, como mostra o Quadro 2.

Quadro 2 - Protocolo de análise documental e consistência técnica de estudos ambientais

\begin{tabular}{|c|c|c|c|c|}
\hline Critérios & \multicolumn{3}{|c|}{ Descrição } & Pontos \\
\hline \multirow{17}{*}{ Informação } & \multirow{17}{*}{$\begin{array}{l}\text { Os dados necessários para identificação } \\
\text { e análise dos impactos são formalmente } \\
\text { apresentados e analisados }\end{array}$} & \multirow{6}{*}{ Diagnóstico ambiental } & Não & 0 \\
\hline & & & Sim, com omissões importantes & 1 \\
\hline & & & Sim, mas insuficiente para análise & 2 \\
\hline & & & Sim, mas de difícil compreensão & 3 \\
\hline & & & Sim, com poucas correções necessárias & 4 \\
\hline & & & Sim, apresetação exata e adequada & 5 \\
\hline & & \multirow{6}{*}{$\begin{array}{l}\text { Características técnicas } \\
\text { do projeto }\end{array}$} & Não & 0 \\
\hline & & & Sim, com omissões importantes & 1 \\
\hline & & & Sim, mas insuficiente para análise & 2 \\
\hline & & & Sim, mas de difícil compreensão & 3 \\
\hline & & & Sim, com poucas correções necessárias & 4 \\
\hline & & & Sim, apresetação exata e adequada & 5 \\
\hline & & \multirow{5}{*}{$\begin{array}{l}\text { Características técnicas de } \\
\text { projetos alternativos }\end{array}$} & Não & 0 \\
\hline & & & Sim, com omissões importantes & 1 \\
\hline & & & Sim, mas insuficiente para análise & 2 \\
\hline & & & Sim, com poucas correções necessárias & 3 \\
\hline & & & Sim, apresetação exata e adequada & 4 \\
\hline \multirow{3}{*}{ Documentação } & \multirow{3}{*}{\multicolumn{2}{|c|}{ As fontes de informação são claramente referidas }} & Não & 0 \\
\hline & & & Parcialmente & 1 \\
\hline & & & Sim & 2 \\
\hline \multirow{9}{*}{ Levantamento } & \multirow{9}{*}{$\begin{array}{l}\text { Os levantamentos de dados primários } \\
\text { e secundários são descritos com } \\
\text { metodologia, resultados e interpretação }\end{array}$} & \multirow{3}{*}{$\begin{array}{l}\text { Dados e informações } \\
\text { ambientais }\end{array}$} & Não & 0 \\
\hline & & & Parcialmente & 1 \\
\hline & & & Sim & 2 \\
\hline & & \multirow{3}{*}{ Dados e informações sociais } & Não & 0 \\
\hline & & & Parcialmente & 1 \\
\hline & & & Sim & 2 \\
\hline & & \multirow{3}{*}{$\begin{array}{l}\text { Dados e informações } \\
\text { econômicas }\end{array}$} & Não & 0 \\
\hline & & & Parcialmente & 1 \\
\hline & & & Sim & 2 \\
\hline \multirow{3}{*}{ Metodologia } & \multirow{3}{*}{\multicolumn{2}{|c|}{$\begin{array}{l}\text { Técnicas usadas para análise dos impactos são descritas e usadas de } \\
\text { acordo com a descrição apresentada }\end{array}$}} & Não & 0 \\
\hline & & & Sim, com limitações técnicas & 1 \\
\hline & & & Sim, bastante clara & 2 \\
\hline
\end{tabular}

Continua... 


\section{Continuação}

\begin{tabular}{|c|c|c|c|c|}
\hline Critérios & \multicolumn{3}{|c|}{ Descrição } & Pontos \\
\hline \multirow{3}{*}{ Coerência } & \multirow{3}{*}{\multicolumn{2}{|c|}{ Dados apresentados são usados para a análise dos impactos }} & Não & 0 \\
\hline & & & $\begin{array}{l}\text { Sim, parcialmente alguns são } \\
\text { desconsiderados e/ou omitidos }\end{array}$ & 1 \\
\hline & & & Sim, de forma objetica e multidisciplinas & 2 \\
\hline \multirow{6}{*}{ Quantificação } & \multirow{6}{*}{ Estimativas quantitativas aplicadas } & \multirow{3}{*}{ Na área afetada } & Não & 0 \\
\hline & & & Sim, parcialmente/com algumas deficiências & 1 \\
\hline & & & Sim, claramente & 2 \\
\hline & & \multirow{3}{*}{ Nas atividades do projeto } & Não & 0 \\
\hline & & & Sim, parcialmente/com algumas deficiências & 1 \\
\hline & & & Sim, claramente & 2 \\
\hline \multirow{4}{*}{ Consistência } & \multirow{4}{*}{\multicolumn{2}{|c|}{$\begin{array}{l}\text { Definição prévia e aplicação de critérios de avaliação da importância dos } \\
\text { impactos previstos }\end{array}$}} & Não & 0 \\
\hline & & & Sim, mas com aplicação ilógica & 1 \\
\hline & & & Sim, mas com aplicação inconsistente & 2 \\
\hline & & & Sim, com aplicação consistente & 3 \\
\hline \multirow{6}{*}{ Objetividade } & \multirow{3}{*}{\multicolumn{2}{|c|}{ Análises e conclusões são imparciais }} & Não & 0 \\
\hline & & & Parcialmente & 1 \\
\hline & & & Sim & 2 \\
\hline & \multirow{3}{*}{\multicolumn{2}{|c|}{ Impactos relevantes são destacados }} & Não & 0 \\
\hline & & & Parcialmente & 1 \\
\hline & & & Sim & 2 \\
\hline \multirow{3}{*}{ Especificidade } & \multirow{3}{*}{\multicolumn{2}{|c|}{ Medidas mitigadoras estão relacionadas aos impactos previstos }} & Não & 0 \\
\hline & & & Parcialmente & 1 \\
\hline & & & Sim & 2 \\
\hline \multirow{9}{*}{ Auditabilidade } & \multirow{9}{*}{$\begin{array}{l}\text { Programa de acompanhamento e } \\
\text { monitoramente de medidas mitigadoras } \\
\text { (os impactos positivos e negativos, } \\
\text { indicando os fatores e parâmetros a } \\
\text { serem considerados) }\end{array}$} & \multirow{3}{*}{$\begin{array}{l}\text { Medidas mitigadoras } \\
\text { apresentadas estão de } \\
\text { acordo com os resultados da } \\
\text { avaliação de impactos }\end{array}$} & Não & 0 \\
\hline & & & Sim, parcialmente/com algumas deficiências & 1 \\
\hline & & & Sim, totalmente & 2 \\
\hline & & \multirow{3}{*}{$\begin{array}{l}\text { Medidas mitigadoras } \\
\text { consistentes e detalhadas }\end{array}$} & Não & 0 \\
\hline & & & Sim, parcialmente/com algumas deficiências & 1 \\
\hline & & & Sim, totalmente & 2 \\
\hline & & \multirow{3}{*}{$\begin{array}{l}\text { Rastreabilidade (medidas } \\
\text { mitigadoras são formuladas } \\
\text { para permitir a verificaçãa } \\
\text { posterior de sua aplicação e } \\
\text { eficiência }\end{array}$} & Não & 0 \\
\hline & & & Sim, parcialmente/com algumas deficiências & 1 \\
\hline & & & Sim, totalmente & 2 \\
\hline \multicolumn{4}{|l|}{ Escore total } & 45 \\
\hline
\end{tabular}

Fonte: Baseado na Resolução Conama n 01/1986, Bojórquez-Tapia \& Garcia (1998), Lee (1999), Sánchez (2008), Viegas (2009) e Canter et al. (2014)

Desse modo, os processos de licenciamento, com seus estudos ambientais selecionados, são analisados e enquadrados na descrição dos critérios do referido protocolo, obtendo-se, assim, pontuações relativas à sua qualidade documental e consistência técnica dos dados e informações apresentados. Estes, são então direcionados ao julgamento quanto aos aspectos de clareza, coerência e rigor técnico-científico, uma vez que essa ferramenta tem a finalidade de demonstrar quantitativamente a coerência técnica existente na composição de estudos ambientais de obras de intervenções em cursos d'água a partir da consideração de elementos e fatores definidos em legislação ambiental e em TRs de processos de licenciamento ambiental dessa tipologia objeto de investigação.

Por fim, como forma de classificar a coerência técnico-documental dos processos analisados, estes são enquadrados de acordo com a pontuação total obtida, no Quadro 3, a qual tem sua escala de gradação baseada no valor do escore total do protocolo (45 pontos), e estruturada a partir do modelo de Escala de Likert (LIKERT, 1932; DALMORO \& VIEIRA, 2013). 
Quadro 3 - Escala de classificação de coerência técnico-documental por pontuação dos estudos ambientais dos projetos de intervenções em cursos d’água

\begin{tabular}{|c|c|c|c|c|}
\hline $\begin{array}{c}\text { Totalmente } \\
\text { incoerente }\end{array}$ & $\begin{array}{c}\text { Muito } \\
\text { incoerente }\end{array}$ & Pouco coerente & Muito coerente & $\begin{array}{c}\text { Totalmente } \\
\text { coerente }\end{array}$ \\
\hline 1 a 9 & 10 a 18 & 19 a 27 & 28 a 36 & 37 a 45 \\
\hline \multicolumn{4}{|c|}{ Fonte: Elaborado pela autora } \\
\hline
\end{tabular}

\section{RESULTADOS E DISCUSSÃO}

A partir da análise dos documentos e estudos ambientais dos citados processos de licenciamento ambiental, as informações e os dados obtidos foram definidos e enquadrados conforme parâmetros estabelecidos no protocolo de análise elaborado. Desse modo, a qualidade documental e a consistência técnica desses estudos foram qualiquantificados de acordo com a escala de classificação de coerência técnicodocumental por pontuação, como forma de demonstração de clareza, coerência e rigor técnico-científico (Quadro 4):

Quadro 4 - Classificação de coerência técnicodocumental por pontuação, dos estudos ambientais dos projetos de intervenções em cursos d’água

\begin{tabular}{|c|c|c|}
$\begin{array}{c}\mathbf{N}^{\circ} \text { de } \\
\text { identificação } \\
\text { do processo }\end{array}$ & $\begin{array}{c}\text { Pontuação obtida } \\
\text { no Protocolo } \\
\text { análise }\end{array}$ & $\begin{array}{c}\text { Classificação de coerência } \\
\text { técnico-documental }\end{array}$ \\
\hline 01 & 18 & Muito incoerente \\
\hline 02 & 18 & Muito incoerente \\
\hline 03 & 31 & Muito coerente \\
\hline 04 & 26 & Pouco coerente \\
\hline 05 & 26 & Pouco coerente \\
\hline 06 & 17 & Muito incoerente \\
\hline 07 & 20 & Pouco coerente \\
\hline 08 & 38 & Totalmente coerente \\
\hline 09 & 28 & Muito coerente \\
\hline 10 & 12 & Muito incoerente \\
\hline & Fonte: Elaborada pela autora \\
\hline
\end{tabular}

Considerando a pontuação máxima estabelecida no Protocolo de análise (Quadro 2), observa-se na Tabela 1 a pontuação detalhada por critérios. No geral, os estudos ambientais analisados apresentam boa qualidade de informações técnicas sobre o projeto, com diagnóstico ambiental satisfatório, exposição das informações ambientais, estimativas quantitativas aplicadas ao projeto e especificidade e auditabilidade satisfatórias referentes às medidas mitigadoras diante dos impactos previstos e sobre os resultados da avaliação de impactos.

Todavia, entre as pontuações alcançadas, verifica-se que nesses projetos de intervenções, em sua maioria, não foram apresentados projetos alternativos, as fontes de informações documentais não são claramente referidas, dados sociais e econômicos não são tratados de forma direta e, por muitas vezes, são desconsiderados, como também, as análises e conclusões não são imparciais.

Por fim, destaca-se que nenhum dos processos analisados obteve a pontuação máxima de 45 (quarenta e cinco) pontos, tendo em sua maioria, valores entre 25 e 30 pontos, podendo-se classificar como de pouca coerência técnicodocumental. 
TABELA 1 - Pontuação dos estudos ambientais referentes aos projetos de intervenções em cursos d'água, a partir da aplicação do Protocolo de análise técnico-documental

\begin{tabular}{|c|c|c|c|c|c|c|c|c|c|c|c|c|}
\hline Critérios & \multicolumn{2}{|c|}{ Descrição } & $\begin{array}{c}\text { Projeto } \\
1\end{array}$ & $\begin{array}{l}\text { Projeto } \\
2\end{array}$ & $\begin{array}{l}\text { Projeto } \\
3\end{array}$ & $\begin{array}{l}\text { Projeto } \\
4\end{array}$ & $\begin{array}{l}\text { Projeto } \\
5\end{array}$ & $\begin{array}{l}\text { Projeto } \\
6\end{array}$ & $\begin{array}{l}\text { Projeto } \\
7\end{array}$ & $\begin{array}{l}\text { Projeto } \\
8\end{array}$ & $\begin{array}{l}\text { Projeto } \\
9\end{array}$ & $\begin{array}{l}\text { Projeto } \\
10\end{array}$ \\
\hline \multirow{3}{*}{ Informação } & \multirow{3}{*}{$\begin{array}{l}\text { Os dados necessários } \\
\text { para identificação e } \\
\text { análise dos impactos } \\
\text { são formalmente } \\
\text { apresentados e } \\
\text { analisados }\end{array}$} & $\begin{array}{l}\text { Diagnóstico } \\
\text { ambiental }\end{array}$ & 2 & 1 & 4 & 4 & 4 & 3 & 4 & 5 & 4 & 2 \\
\hline & & $\begin{array}{l}\text { Características } \\
\text { técnicas } \\
\text { do projeto }\end{array}$ & 4 & 2 & 5 & 2 & 4 & 4 & 4 & 4 & 4 & 4 \\
\hline & & $\begin{array}{l}\text { Características } \\
\text { técnicas } \\
\text { de projetos } \\
\text { alternativos }\end{array}$ & 0 & 0 & 1 & 0 & 1 & 0 & 0 & 4 & 0 & 0 \\
\hline Documentação & \multicolumn{2}{|c|}{$\begin{array}{l}\text { As fontes de informação são claramente } \\
\text { referidas }\end{array}$} & 1 & 1 & 1 & 1 & 1 & 0 & 1 & 0 & 1 & 1 \\
\hline \multirow{3}{*}{ Levantamento } & \multirow{3}{*}{$\begin{array}{l}\text { Os levantamentos } \\
\text { de dados primários } \\
\text { e secundários são } \\
\text { descritos com } \\
\text { metodologia, resultados } \\
\text { e interpretação }\end{array}$} & $\begin{array}{l}\text { Dados e } \\
\text { informações } \\
\text { ambientais }\end{array}$ & 1 & 2 & 1 & 1 & 1 & 1 & 1 & 2 & 2 & 0 \\
\hline & & $\begin{array}{l}\text { Dados e } \\
\text { informações } \\
\text { sociais }\end{array}$ & 0 & 1 & 1 & 1 & 0 & 0 & 0 & 2 & 2 & 0 \\
\hline & & $\begin{array}{l}\text { Dados e } \\
\text { informações } \\
\text { econômicas }\end{array}$ & 0 & 1 & 1 & 1 & 1 & 0 & 0 & 1 & 1 & 0 \\
\hline Metodologia & \multicolumn{2}{|c|}{$\begin{array}{l}\text { Técnicas usadas para análise dos impactos } \\
\text { são descritas e usadas de acordo com a } \\
\text { descrição apresentada }\end{array}$} & 1 & 2 & 1 & 2 & 0 & 1 & 1 & 1 & 1 & 0 \\
\hline Coerência & \multicolumn{2}{|c|}{$\begin{array}{l}\text { Dados apresentados são usados para a } \\
\text { análise dos impactos }\end{array}$} & 1 & 1 & 2 & 2 & 1 & 1 & 1 & 2 & 1 & 0 \\
\hline \multirow[b]{2}{*}{ Quantificação } & \multirow{2}{*}{$\begin{array}{l}\text { Estimativas } \\
\text { quantitativas aplicadas }\end{array}$} & Na área afetada & 1 & 1 & 1 & 1 & 1 & 1 & 1 & 1 & 1 & 0 \\
\hline & & $\begin{array}{l}\text { Nas atividades } \\
\text { do projeto }\end{array}$ & 1 & 1 & 2 & 2 & 1 & 1 & 1 & 2 & 1 & 1 \\
\hline Consistência & \multicolumn{2}{|c|}{$\begin{array}{l}\text { Definição prévia e aplicação de critérios } \\
\text { de avaliação da importância dos impactos } \\
\text { previstos }\end{array}$} & 0 & 0 & 2 & 2 & 2 & 0 & 0 & 3 & 1 & 0 \\
\hline \multirow{2}{*}{ Objetividade } & \multicolumn{2}{|c|}{ Análises e conclusões são imparciais } & 1 & 0 & 1 & 1 & 1 & 0 & 0 & 2 & 0 & 0 \\
\hline & \multicolumn{2}{|c|}{ Impactos relevantes são destacados } & 1 & 1 & 2 & 1 & 2 & 0 & 0 & 2 & 1 & 0 \\
\hline Especificidade & \multicolumn{2}{|c|}{$\begin{array}{l}\text { Medidas mitigadoras estão relacionadas } \\
\text { aos impactos previstos }\end{array}$} & 1 & 1 & 2 & 2 & 2 & 2 & 2 & 2 & 2 & 1 \\
\hline \multirow{3}{*}{ Auditabilidade } & \multirow{3}{*}{$\begin{array}{l}\text { Programa de } \\
\text { acompanhamento e } \\
\text { monitoramente de } \\
\text { medidas mitigadoras } \\
\text { (os impactos positivos e } \\
\text { negativos, indicando os } \\
\text { fatores e parâmetros a } \\
\text { serem considerados) }\end{array}$} & $\begin{array}{l}\text { Medidas } \\
\text { mitigadoras } \\
\text { apresentadas } \\
\text { estão de } \\
\text { acordo com os } \\
\text { resultados da } \\
\text { avaliação de } \\
\text { impactos }\end{array}$ & 1 & 1 & 2 & 1 & 2 & 1 & 2 & 2 & 2 & 1 \\
\hline & & $\begin{array}{l}\text { Medidas } \\
\text { mitigadoras } \\
\text { consistentes e } \\
\text { detalhadas } \\
\end{array}$ & 1 & 1 & 1 & 1 & 1 & 1 & 1 & 2 & 2 & 1 \\
\hline & & $\begin{array}{l}\text { Rastreabilidade } \\
\text { (medidas } \\
\text { mitigadoras } \\
\text { são formuladas } \\
\text { para permitir } \\
\text { a verificação } \\
\text { posterior de } \\
\text { sua aplicação e } \\
\text { eficiência }\end{array}$ & 1 & 1 & 1 & 1 & 1 & 1 & 1 & 1 & 2 & 1 \\
\hline \multicolumn{3}{|l|}{ Pontuação total } & 18 & 18 & 31 & 26 & 26 & 17 & 20 & 38 & 28 & 12 \\
\hline
\end{tabular}




\section{CONSIDERAÇÕES FINAIS}

Apesar de as pontuações atribuídas aos estudos ambientais terem como base a utilização do Protocolo de análise elaborado e de serem indicadas pelo pesquisador-observador, entende-se que, embora sejam documentos exigidos por Lei, os Estudos Ambientais em muitos casos não apresentam conformidade em relação à apresentação de informações e dados técnicos essenciais ao processo de Avaliação de Impacto Ambiental (AIA), dificultando tecnicamente as análises para o devido licenciamento ambiental da atividade/ empreendimento em questão.

Sabe-se que a elaboração dos estudos ambientais é de responsabilidade de profissionais especialistas na área, porém em muitos estudos, como mostram os resultados apresentados, a sobreposição de laudos técnicos e descrições separadas de elementos ambientais, bem como de aspectos sociais e econômicos, pode levar à interpretação apenas pontual do objeto de estudo. Esse fato pode ser atribuído à falta de orientações e procedimentos padrões quanto à elaboração desses documentos e apresentação das informações, contribuindo, assim, para a falta de precisão, clareza e coerência técnica que deve subsidiar a análise técnica dos órgãos ambientais responsáveis pela tomada de decisão.

Desse modo, pode-se compreender que a prática de elaboração de estudos ambientais para a AIA, pode, então, acontecer simplesmente pelo formalismo documental do processo de licenciamento ambiental, visando à obtenção de licenças ambientais, até mesmo para os casos de empreendimentos e atividades de significativos impactos ambientais, uma vez que, apesar de não atenderam a determinações jurídicas e técnicas, os processos analisados podem ser artifícios de solicitações atendidas.

Além disso, embora a pesquisa tenha como fundamento a aplicação do protocolo em um quantitativo limitado de estudos ambientais de projetos de intervenções em cursos d'água, considera-se que o seu propósito principal foi alcançado. Com esta ferramenta aprimorada, foi possível classificar a coerência técnico-documental desses estudos de projetos específicos como, também, o mesmo pode ser empregado para outras diferentes tipologias com distintos objetos de avaliação ambiental.

No mais, é importante também ressaltar que o não cumprimento de um Termo de Referência (TR) e/ou de recomendações de equipe técnica especializada do órgão ambiental pode motivar a não aprovação de um determinado projeto e que o protocolo de análise elaborado pode ser um instrumento de aplicação rápida, que pode classificar e apresentar a qualidade da consistência documental e técnica dos estudos ambientais.

\section{CONTRIBUIÇÃO DOS AUTORES}

Todos os autores contribuíram de forma igualitária.

\section{REFERÊNCIAS}

ABSY, L. A.; ASSUNÇÃO, F. N. \& FARIA, S. C. Avaliação de Impacto Ambiental: agentes sociais, procedimentos e ferramentas. Brasília: IBAMA, 1995.

ARAÚJO, D. C.; SILVA, P. O.; CURI, W. F.; \& CABRAL, J. Multicriteria analysis applied to the management of urban pluvial waters. Revista Brasileira de Recursos Hídricos, v. 22, n.18, 2017.

BELL, S., \& MORSE, S. Sustainability Indicators: Measuring the Immeasurable?. London: Earthscan, 2008.

BOJÓRQQUEZ-TAPIA, L. A. \& GARCIÁ, O. An approach for evaluating EIAs - Deficiencies of EIA in Mexico. Environmental Impact Assessment Review, v. 18, 1998. pp. 217 - 240.

BOND, A. et al. Learning How to Deal with Values, Frames and Governance in Sustainability Appraisal. Regional Studies, v. 45, n. 08, 2011.pp. 1157-1170.

BRAGAGNOLO, C. et al. Streamlining or sidestepping? Political pressure to revise environmental licensing and EIA in Brazil. Environmental Impact Assessment Review, n. 65, 2017. pp. 86-90. 
BRASIL. Lei Federal $n^{\circ}$ 6.938, de 31 de agosto de 1981. Política Nacional de Meio Ambiente. Disponível em http://www.planalto. gov.br/ccivil_03/leis/L6938.htm. Acesso em 07 de junho de 2016.

CANTER, L. W.; CHAWLA, M. K.; SWOR, C. T. Addressing trend-related changes within cumulative effects studies in water resources planning. Environmental Impact Assessment Review, n. 44. 2014. pp. 58-66.

CARDOSO, A. S. \& BAPTSTA, M. B. Metodologia para Avaliação de Alternativas de Intervenção em Cursos de Água em Áreas Urbanas. Revista Brasileira de Recursos Hídricos, v. 16, n. 01 de jan./ mar. 2011. pp. 129-139.

CARDOSO, O. R. et al. Análise de fragilidade ambiental na bacia do rio Pardo - RS, frente à instalação de pequenas centrais hidrelétricas (PCHs). Revista Brasileira de Recursos Hídricos, v. 20, n. 02, abr./jun., 2015. pp. 507-522.

CARVALHO, A. T. F.; GIRÃO, O. \& CABRAL, J. J. da S. P. Efeitos de revestimento de canal e impermeabilização do solo à dinâmica de inundação do rio Arrombados - PE. Revista Geociências - UNESP, v. 36, n. 01, 2017. pp. 76-88.

CHRISTOFOLETTI, A. Análise de sistemas em Geografia. São Paulo: Hucitec, 1979.

COELHO, A. N. Geomorfologia fluvial de rios impactados por barragens. Caminhos de Geografia, v. 09, n. 26, 2008. pp. 16-32.

CONSELHO NACIONAL DE MEIO AMBIENTE - CONAMA. Resolução Conama nº 01, de 23 de Janeiro de 1986. Disponível: http:// www.mma.gov.br/port/conama/res/res86/res0186.html. Acesso em 24 de Outubro de 2016.

CRUZ, R. C., et al. Tendências na Análise de Impactos da Implementação de Barragens: Lições do Estudo de Caso das Barragens de Uso Múltiplo da Bacia do Rio Santa Maria. Revista Brasileira de Recursos Hídricos, v. 15, n. 01, jan./mar. 2010. pp. 47-66.

FISCHER, T. \& JHA-THAKUR, U. Environmental Assessment and Management Related Master Level Degree Programmes in the EUA: baseline, trends, challenges and opportunities. Journal of Environmental Assessment Policy and Management, v. 15, n. 04, 2013. pp. 01-26.

GALÁS, S. et al. Environmental Impact Assessment in the Visegrad Group countries. Environmental Impact Assessment Review, n. 55, 2015. pp. 11-20.

HAASE, D. Effects of urbanisation on the water balance - A long-term trajectory. Environmental Impact Assessment Review, n. 29, 2009. pp. 211-219.

LACERDA, C. S. \& CÂNDIDO, G. A. Modelos de indicadores de sustentabilidade para gestão de recursos hídricos. Campina Grande: EDUEPB, 2003.

LEE, N.; COLLEY, R.; BONDE, J. \& SIMPSON, J. Reviewing the quality of environmental statements and environmental appraisals. Manchester: University of Manchester, 1999. 44p.
LEUNG, W. et al. A review of uncertainty research in impact assessment. Environmental Impact Assessment Review, n. 50, 2015. pp. 116-123.

MARTINET, V. A characterization of sustainability with indicators. Journal of Environmental Economics and Management, n. 61, 2011. pp. 183-197.

MILARÉ, E. Direito do ambiente: a gestão ambiental em foco: doutrina, jurisprudência, glossário. São Paulo: Revista dos Tribunais, 2009.

MINISTÉRIO DO MEIO AMBIENTE. Avaliação ambiental estratégica. Brasília: MMA, 2002.

MINISTÉRIO DO MEIO AMBIENTE. Ministério do Meio Ambiente. Disponível: http://www.mma.gov.br/port/conama/. Acesso em 25 de junho de 2018.

MINISTÉRIO DO MEIO AMBIENTE. Portal Nacional de Saneamento Ambiental. Disponível em: http://pnla.mma.gov.br/. Acesso em 19 de fevereiro de 2017.

MIRRA, A. L. Impacto ambiental: aspectos da legislação brasileira. São Paulo: Juarez de Oliveira, 2002.

MORAES, S. M., \& SANTOS, E. M. Avaliação de Impactos Ambientais (AIA): instrumento importante na sustentabilidade de projetos rodoviários. Revista da FARN, v. 03, n. 01-02, 2004. pp. 45-58.

MOREIRA, I. D. Avaliação de Impacto Ambiental. 1985. Disponível em: www.uff.br/estudossociaisambientais/Avadeimpactoambiental.doc. Acesso em 17 de fevereiro de 2018.

MORGAN, R. Environmental impact assessment: the state of art. Impact Assessment and Project Appraisal, v. 30, n. 01, 2012. pp. 05-14.

NEVES, F. F. et al. Avaliação de impactos ambientais no contexto de aplicação dos Instrumentos de Política Ambiental. Interface Tecnológica, v. 10, n. 01, 2013. pp. 83-94.

PATTERSON, M. ISEE Conference 2010. Disponível em: http:// www.isee2010.org/full_papers.php?level=0\&cat=-. Acesso em 05 de Agosto de 2017.

PERMINOVA, T. et al. Methods for land use impact assessment: A review. Environmental Impact Assessment Review, n. 60, 2016. pp. 64-74.

POPE, J. et al. Reconceptualising sustainability assessment. Environmental Impact Assessment Review, n. 62, 2017. pp. 205-215.

REZENDE, O. M.; MIGUEZ, M. G. \& VERÓL, A. P. Manejo de Águas Urbanas e sua Relação com o Desenvolvimento Urbano em Bases Sustentáveis Integradas - Estudo de Caso dos Rios Pilar-Calombé, em Duque de Caxias/RJ . Revista Brasileira de Recursos Hídricos, v. 18, n. 02, abr/jun, 2013. pp. 149-163.

SÁNCHEZ, L. E. Avaliação Ambiental Estratégica e sua aplicação no Brasil. 2008. Disponível em: http://www.iea.usp.br/publicacoes/textos/aaeartigo.pdf. Acesso em 27 de maio de 2017. 
SÁNCHEZ, L. E. Avaliação de Impacto Ambiental: conceitos e métodos. São Paulo: Oficina de textos, 2013. 583p.

STAMM, H. R. Método de Avaliação de Impacto Ambiental (AIA) em projetos de grande porte: estudo de caso de uma usina termelétrica. 2003. Tese (Doutorado em Engenharia de Produção) Programa de Pós-graduação em Engenharia de Produção. Florianópolis: Universidade Federal de Santa Catarina, 2003.

TEIXEIRA, D. M. Os procedimentos do licenciamento ambiental. Boletim Científico Escola Superior do Ministério Público da União, ano 09, n. 32-33, jan./dez. 2010. pp. 37-69.

TORO, J. et al. A qualitative method proposal to improve environmental impact assessment. Environmental Impact Assessment Review, n. 43, 2013. pp. 9-20.

VALINHAS, M. M. Licenciamento ambiental e sustentabilidade. Boletim do Observatório Ambiental Alberto Ribeiro Lamego, v. 4, n. 2, jul./dez. 2010, pp. 231-246.
VAN BELLEN, H. M. Indicadores de sustentabilidade - um levantamento dos principais sistemas de avaliação. Cadernos EBAPE.BR, v. 02, n. 01, mar. 2004. pp. 01-14.

VIEGAS, C. V. Atividades de gestão do conhecimento na elaboração do Estudo de Impacto Ambiental. 2009. 362f. Tese (Doutorado em Engenharia e Gestão do Conhecimento) - Programa de Pós-graduação em Engenharia e Gestão do Conhecimento. Florianópolis: Universidade Federal de Santa Catarina, 2009.

WILLIAMS, A. \& DUPUY, K. Deciding over nature: Corruption and environmental impact assessments. Environmental Impact Assessment Review, n. 65, 2017. pp. 118-124.

ZANDONADI, L. U.; MENDONÇA, A. F. \& REIS, J. T. Outorga de lançamento de efluentes em rios - estimativas de vazões de diluição. Revista Brasileira de Recursos Hídricos, v. 20, n. 02jan./mar. 2015. pp. 179-191. 